\title{
Virtual Patient Cases for Active Student Participation in Nursing Education -Students' Learning Experiences
}

\author{
Elenita Forsberg*, Berit Bäcklund, Eva Hjort Telhede, Staffan Karlsson \\ School of Health and Welfare, Halmstad University, Halmstad, Sweden \\ Email: *elenita.forsberg@hh.se
}

How to cite this paper: Forsberg, E., Bäcklund, B., Telhede, E. H., \& Karlsson, S. (2019). Virtual Patient Cases for Active Student Participation in Nursing Education-Students' Learning Experiences. Creative Education, 10, 1475-1491. https://doi.org/10.4236/ce.2019.107108

Received: May 13, 2019

Accepted: July 9, 2019

Published: July 12, 2019

Copyright $\odot 2019$ by author(s) and Scientific Research Publishing Inc. This work is licensed under the Creative Commons Attribution International License (CC BY 4.0).

http://creativecommons.org/licenses/by/4.0/

\section{(c) () Open Access}

\begin{abstract}
Virtual Patient cases (VP cases) promote learning, teaching, and assessment of clinical reasoning and can stimulate and motivate active learning experiences in nursing education. The aim of the study was to investigate the use of VP cases for active student participation in nursing education regarding students' learning experiences of clinical reasoning. After an intervention using VP cases in the graduate nursing program, 174 evaluation questionnaires were collected from the students. The questionnaire consisted of open-ended questions that covered students' learning experiences using VP cases. Deductive content analysis was used with a focus on the students' learning experiences. The results showed that the use of the VP cases provided a comprehensive view of the patient and encouraged the students to broaden their thinking and helped them in drawing conclusions and in structuring their problem-solving. The VP cases also stimulated their learning process and reflection. Their knowledge was challenged, and this motivated them to search for more knowledge that was then followed up in the VP cases. The students found that the VP cases provided support in translating theoretical knowledge into clinical reasoning, and they facilitated the application of theory in practice and encouraged the students to use their clinical reasoning. The VP cases allowed for self-evaluation, which was a motivating force and increased their awareness of their abilities for clinical reasoning. Learning experiences from VP cases seem to be applicable in higher education and seem especially useful in enabling nursing students to apply theory in their clinical practice. Experiential learning theory supports the learning experiences from VP cases in clinical reasoning. In addition, working with VP cases seems to promote active student participation.
\end{abstract}

\section{Keywords}

Virtual Patient, Active Student Participation, Nursing Education, Learning 
Experiences, Clinical Reasoning

\section{Introduction}

VP cases promote learning, teaching, and assessment of clinical reasoning and can stimulate and motivate active learning experiences in nursing education. Today's students have grown up in a digital world, and they welcome elements of e-learning activities in their education (Mishra, Rani, \& Bhardwaj, 2017). In the digital era, the role of higher education needs to be developed. Governments advocate the development of digital environments that can offer flexible solutions that enable learning regardless of location or time and that support lifelong learning, and the universities have to integrate digital skills in all education programs in order to better meet the needs of the labor market (SOU, 2016: p. 89). Many universities are currently working on developing digitalization strategies for the development of physical and digital learning environments to support student learning, and there has been a shift towards more active student learning strategies in higher education (Barrineau, Engström, \& Schnaas, 2019).

In Sweden, graduate nurse education is a three-year bachelor program that leads to a license to practice as a registered nurse. The nursing program has learning goals such as demonstrated clinical reasoning abilities and clinical skills in nursing and medical sciences. Nurses' clinical reasoning process can be described as how "nurses collect cues, process the information, come to an understanding of a patient's problem or situation, plan and implement interventions, evaluate outcomes, and reflect and learn from these processes" (Levett-Jones et al., 2010: p. 516). To develop clinical skills and clinical reasoning abilities during nursing education is essential in order to prepare for the nursing profession (Jessee \& Tanner, 2016; Johannesson, Silén, Kvist \& Hult, 2013), and the healthcare system requires effective and evidence-based clinical decision skills in order to minimize the risk to patient safety. Studies have identified a lack of clinical reasoning skills among nurses, and thus it appears that pedagogical approaches do not always facilitate the development of nurses' clinical reasoning (Hunter \& Arthur, 2016). To teach and learn clinical reasoning is challenging because of its complexity, and it is difficult to make the clinical reasoning process visible and easy for the nursing students to grasp (Delany \& Golding, 2014). Therefore, healthcare educators need to create learning activities that support students' ability to comprehend the clinical reasoning process (Bloomfield, FordhamClarke, Pegram, \& Cunningham, 2010).

VP cases have been found to be a valuable tool for learning, teaching, and assessing clinical reasoning (Berman, Durning, Fischer, Huwendiek, \& Triola, 2016; Cook \& Triola, 2009; Cook, Erwin, \& Triola, 2010; Forsberg, Ziegert, Georg, \& Fors, 2011; Forsberg, Ziegert, Hult, \& Fors, 2014; Georg \& Zary, 2014). VPs can be defined as "interactive computer simulations of real-life clinical sce- 
narios for the purpose of healthcare and medical training, education and assessment" (Ellaway, Poulton, Fors, McGee, \& Albright, 2008: p. 170; Kononowicz, Zary, Edelbring, Corral, \& Hege, 2015). A VP case can help to transform theoretical knowledge into clinical practice (Edelbring, Dastmalchi, Hult, Lundberg, \& Dahlgren, 2011). Based on learning outcomes, teachers can design various VP cases, from commonly occurring patient problems to complex diseases or emergencies. In the VP system, the student can take the role of a nurse and meet patients in different care settings. VP cases provide a safe environment in which to train the steps in the clinical-reasoning process such as collecting cues from patient interview questions, physical exams, and ordered tests and then making decisions about the diagnosis and treatment/management plan for the patient. The VP system promotes self-regulated learning by allowing the student to receive feedback on completed interactions and suggestions for diagnosis and treatment immediately after problem-solving the VP case. VP cases can also prepare the nursing students prior to their clinical practice to be aware of what kind of patients they are likely to meet and what kinds of clinical competences are expected (Forsberg, Ziegert, Hult, \& Fors, 2016).

The purpose of this project was to implement VP cases in graduate nursing education in order to train clinical reasoning and to support active student participant (ASP). Our intention was to reduce lectures by teachers in order to create more quality in teaching through, for example, more time for seminar discussions of the VP cases where students learn to practice peer tutoring. The term ASP means different things depending on the context in which it is used (Bengtson et al., 2017), but common to the different definitions of ASP is increased student participation in teaching. For example, in the seminars for the VP cases the students can be a resource in each other's learning. Through ASP the students take on a more active role in their own learning, which increases their motivation and supports in-depth learning and promotes understanding of the subject (Barrineau et al., 2019; Bengtson et al., 2017). VP cases also have the potential to stimulate and motivate active learning of the clinical reasoning process (Consorti, Mancuso, Nocioni, \& Piccolo, 2012; Forsberg et al., 2016). However, there is still a lack of knowledge regarding VP cases as a learning activity and how they help graduate nursing students to grasp and comprehend the clinical reasoning process. The aim of the study was to investigate the use of VP cases for ASP in nursing education regarding students' learning experiences of clinical reasoning.

\section{Method}

\subsection{Design}

A qualitative study with narratives.

\subsection{Sample}

In total, 174 questionnaires were included. A convenience sample was provided 
with 116 questionnaires collected during spring semester of 2017 on two occasions and 58 questionnaires collected on two occasions during the autumn semester of 2017. The first occasion was when the VP system was newly implemented and the second was when the VP system was more established. The course in the spring semester included 72 students, and in the autumn semester, the course included 88 students.

\subsection{Intervention}

The intervention using VP cases was provided in the course Human Biomedicine Sciences to Support Nursing II, 15 credits, in the 180-credit graduate nursing program (Bachelor degree). The course was offered in the third semester out of the six semesters of the program.

The VP cases were designed by the lecturers in the course, and the VP system was Web-SP (Web-based Simulated Patient). The Web-SP was developed in the early 1990s at the Karolinska Institute in Sweden (Zary, Johnson, Boberg, \& Fors, 2006) and has been used worldwide in different healthcare education programs, for example, as an assessment instrument in Swedish nursing education (Forsberg et al., 2011) and for training critical thinking (Sunnqvist, Karlsson, Lindell, \& Fors, 2016). The Web-SP system has a number of features, including a waiting room (patient cases that should be used in the course), an introduction to the case, patient interview questions, physical examinations, laboratory tests, $\mathrm{x}$-rays, etc., and features for suggesting appropriate diagnoses and differential diagnoses and treatment and provides justification for decisions about diagnosis and treatment and a feedback section (Bergin \& Fors, 2003). The feedback section shows which patient interview questions, physical exams, and tests were recommended and which ones the student has completed. The student can also compare their free-text response with the VP case maker's proposal.

Prior to working with the VP cases, the students had lectures in medical science concerning diseases of the brain, the vascular system, the chest organs, the abdomen, the kidney, and the endocrine system as well as movement disorders. Written and verbal information was given to the students about the procedure of providing the VP cases when the course was introduced. To support active student participation, the students had to take responsibility for acquiring the individual knowledge for the cases. The VP cases included patients with concussion of the brain, obstructive lung disease, colon cancer, and hyperthyroidism. After completing each VP case, the students were able to ask questions in the follow-up seminars.

\subsection{Instrument}

The evaluation questionnaire asked about students' learning experiences using the VP cases. The following questions with open-ended answers were used:

1) What did you find instructive about completing the VP cases? Describe what you found particularly difficult, important, or interesting. 
2) Did you feel certain or uncertain in your clinical reasoning when you completed the VP cases?

3) How was the agreement between this new knowledge and experience and your previous knowledge and experiences?

4) In what way has this new knowledge and experience strengthened your previous knowledge and experience, and how will you realize this new knowledge and experience in future situations?

The questionnaire was previously used for evaluation of VP cases in postgraduate nursing education (Forsberg et al., 2016).

\subsection{Procedure}

Data collection using questionnaires took place on two occasions in both semesters connected to the evaluation of the VP cases. From each lecture three cases were produced; two were processed during a seminar and one case was processed individually by the students as a VP case. The questionnaires were completed in the classroom and given to the lecturer.

\subsection{Analysis}

Qualitative content analysis was applied (Graneheim \& Lundman, 2004). The open-ended answers were read and reread by the first and last authors to get an overview of the students' learning experiences, while at the same time the second and third authors reviewed the open-ended answers from the evaluation questionnaire. A deductive content analysis (Hsieh \& Shannon, 2005) was used with a focus on the learning experiences from the evaluation questionnaire. Meaning units were extracted according to the aim and were condensed and coded. Preliminary sub-categories and categories were developed and were discussed among the authors until reaching consensus. In addition, sub-categories and categories were validated against the text from the evaluation questionnaires and minor adjustments were made (Table 1).

\subsection{Ethical Considerations}

The students filled in the evaluation questionnaires voluntarily and delivered them anonymously to the lecturer. This study was based on current educational

Table 1. Example of analysis process.

\begin{tabular}{lllr}
\multicolumn{1}{c}{ Meaning units } & Condensed meaning units & Codes & Subcategories \\
\hline $\begin{array}{l}\text { Linking the theory one has } \\
\text { learned to a specific case, } \\
\text { which makes it more realistic. }\end{array}$ & Linking theory to a real case & Applied theory & Apply theory in practice \\
$\begin{array}{l}\text { Think it is important and } \\
\text { interesting to combine web exercises } \\
\text { and patient cases with seminars }\end{array}$ & $\begin{array}{l}\text { Combine web exercises and } \\
\text { patient cases with seminars }\end{array}$ & Combined exercises & Combine theory \\
$\begin{array}{l}\text { I thought it was useful to be skilled } \\
\text { in the reasoning we must } \\
\text { have when we work as a nurse }\end{array}$ & Skilled in reasoning as a nurse & Reasoning skills & clinical reasoning \\
\hline
\end{tabular}


matters regarding the improvement of digital didactic methods in nursing courses. The study was related to normal course improvement, and thus did not need any ethical approval.

\section{Results}

The results showed that use of the VP cases helped the students to broaden their thinking, which improved their ability to draw conclusions and their problem-solving ability when obtaining a comprehensive view of the patient. The VP cases stimulated their learning process and inspired reflection, and their knowledge was challenged and they were motivated to search for more knowledge that was then followed up by the VP system. The students found that the VP cases supported the translation of theoretical knowledge into clinical reasoning. The VP cases facilitated the students in applying theory in practice as well as in combining theory and practice and encouraged their clinical reasoning. The VP system provided a self-evaluation of solved VP cases, which was a motivating force (Table 2).

\subsection{Exercising to Broaden Thinking}

\section{Improve conclusion drawing}

The students described how working with VP cases broadened their thinking, and they were encouraged to analyze patient data in a new way. The students reported that they obtained new knowledge, and they described how the VP cases made them think with more foresight regarding the patient's status and prepared them for carrying out clinical interventions. The approach regarding differential diagnoses was instructive and forced the students to think in a broader way regarding the patient's situation. The request for differential diagnoses contributed to making the students more open-minded regarding alternative diseases.

"What was instructive is that you always learn to think one step further."

"It was interesting to see how different diseases can have similar symptoms, but on further examination it turned out to be something else."

Table 2. Main categories and sub-categories.

\begin{tabular}{ll}
\hline \multicolumn{1}{c}{ Categories } & \multicolumn{1}{c}{ Subcategories } \\
\hline Exercising to broaden thinking & $\begin{array}{l}\text { Improve conclusion drawing } \\
\text { Structure for problem solving } \\
\text { Comprehensive view of the patient }\end{array}$ \\
& $\begin{array}{l}\text { Inspire reflection } \\
\text { Challenge existing knowledge } \\
\text { Stimulating the learning process }\end{array}$ \\
& $\begin{array}{l}\text { Motivate to search for more knowledge } \\
\text { Independent follow-up of knowledge }\end{array}$ \\
Translating theoretical knowledge & $\begin{array}{l}\text { Apply theory in practice } \\
\text { Combine theory and practice } \\
\text { into clinical reasoning }\end{array}$ \\
Encourage clinical reasoning \\
Self-evaluation of knowledge & $\begin{array}{l}\text { Motivational feedback } \\
\text { Awareness of ability }\end{array}$ \\
\hline
\end{tabular}




\section{Structure for problem solving}

The VP cases gave the students a systematic way of getting a holistic view of the patient's situation. The students reported that the VP cases gave them the opportunity to independently think about and solve cases and that new knowledge was combined with previous knowledge to solve the cases. The students also reported that they had become more skilled after solving each VP case and that these experiences were transferred to the next VP cases as well as to their clinical profession.

"I begin to see a system in the thinking".

"From previous VP cases to the latest one, you always ask if there is anything more you need to look at, have you missed anything, what how does the person's everyday life look like ...."

\section{Comprehensive view of the patient}

The students reported that the VP cases developed a better understanding of the patient's illness. They described a more holistic view of the patient and an improved understanding of the course of events. The VP cases invited the students to think about how details are connected, and the students reported how the VP cases taught the importance of not focusing only on one's initial suspicion and of seeking alternative solutions.

"It was a very good method to understand the bigger picture in nursing (status, anamnesis, laboratory samples, diagnosis)".

"You get an overall picture, get to think for yourself, think about how things are connected".

\subsection{Stimulating the Learning Process}

\section{Inspire reflection}

The students reported that the VP cases forced them to think independently and in a new way, and thoughtfulness was needed for consideration. Increased thoughtfulness implied receiving more knowledge and understanding regarding specific diseases. In addition, the students' thoughtfulness regarding the VP case helped them determine which interventions were required. The students reported that the VP cases challenged them to think one step further, which indicated how well theory and practice agreed with each other.

"It is educational to reflect on the different diagnoses because several symptoms recur among the diseases".

"That you get to think for yourself and gain more understanding and knowledge of the specific topics we cover".

\section{Challenge existing knowledge}

Due to the students' early stage in their nursing education, the VP cases challenged them to reason about diagnoses, differential diagnoses, laboratory tests, and medical examinations. The students reported uncertainly about the patient interview questions and about which laboratory tests and examinations they should perform in the various diagnoses in the cases. However, some students reported that they felt certain regarding the expected diagnosis, but unsure how 
to motivate the suggested diagnosis. The many new decisions needed in the VP cases were challenging for the students, and mistakes in problem solving in the VP cases resulted in the students independently developing new and deeper knowledge.

"It was difficult to know what patient interview questions one should ask and how deeply one should get to know the case regarding laboratory sampling and examinations".

"I was becoming a little uncertain because there are many decisions to make that one is not used to".

\section{Motivate to search for more knowledge}

When the students worked with the VP cases, they described how was obvious that they needed to gain more knowledge from the literature and lectures. They used information from the literature for solving the cases, but sometimes it was difficult to find the proper information needed. The students were conscious that they had to be active in searching for solutions to the problems in the VP cases. Overall, the students reported that they had obtained useful knowledge.

"I got to study more when I worked on the case".

"It reinforces me in such a way that I become more confident and I enjoy delving deeper into the subject".

\section{Independent follow-up of knowledge}

The students had to think independently when working on the VP cases. They described how the VP cases followed up their knowledge and showed them whether their thinking was reasonable. The students reported increased learning and how they had obtained new knowledge when working with the VP cases. They thought it was exciting to acquire extensive information and then independently sort through it to find that which is the most important. The students also expressed that their limited knowledge was challenged when the VP case was described only briefly.

"You test your knowledge more, to see if you are thinking correctly or not".

"It was fun; you get a lot of information and have to be able to remove things and sort out the most important information".

\subsection{Translating Theoretical Knowledge into Clinical Reasoning}

\section{Apply theory in practice}

The students described how they used their theoretical knowledge in the VP cases, and they stated that the VP cases were realistically designed. Previously learned theory was applied in practice, and the students reported how the knowledge obtained in the VP cases better prepared them to approach their future work in the nursing profession.

"You have to consider and make use of the knowledge you have learned and put it into a context that feels real'.

"I can use this in future situations".

Combine theory and practice

The students described how the VP cases were clearly connected to theoretical 
teaching and the literature and how their knowledge was strengthened when the theory was combined with VP cases and then followed up in seminars. The students reported that lectures followed by practical exercise in the VP cases improved their knowledge retention and how the VP cases encouraged the students to apply their knowledge in realistic cases.

"I think it is important and interesting to combine web exercises and virtual patient cases with seminars".

"Things are easier to remember when they are connected with a practical case".

\section{Encourage clinical reasoning}

The students found the VP cases to be realistic and similar to practical situations, and the VP cases trained various abilities such as pattern recognition, clinical reasoning, and clinical decision making. The students reported that their skills in detecting the signs and symptoms of conditions and diseases were improved, and they found that the VP cases provided valuable training in learning about patient interviews and in learning about different diagnostic and treatment methods. The students stated that VP cases also made them conscious of their responsibility for patient safety. The students further expressed how the VP cases taught them to recognize the patient's overall situation and how to act with the patient, and they described how the VP case made them more self-confident regarding their professional actions.

"Trains the ability to find/see correlations between signs/symptoms and conditions/illnesses".

"Missing a blood test or an $x$-ray can be crucial for the quality of care".

"It gave me the confidence that I know what needs to be carried out".

\subsection{Self-Evaluation of Knowledge}

\section{Motivational feedback}

The students found the independent training with VP cases to be instructive, and they especially appreciated the follow-up. They expressed how generous feedback facilitated expanded learning. The students also described how the feedback improved their understanding of the cases and worked as a motivating force.

"It was educational that one had to go through the cases independently and then compare one's results with the follow-up".

"What led me forward and increased my understanding was the feedback; however, such feedback should be more detailed".

\section{Awareness of ability}

The feedback from the VP cases gave information to the students about their level of knowledge. Adequate or insufficient knowledge became immediately visible to the student through the feedback, and this was experienced as a way of learning. The students were satisfied when confirmation was established and they were convinced that the solutions were appropriate.

" $A$ good and very effective way to test one's knowledge and good practice for the future". 
"It was a tricky case. I thought it was ileus, while it was cancer as well. However, I was sure of my reasoning after the feedback".

\section{Discussion}

Learning experiences from VP cases seem to be overall applicable in higher education, and acquired skills from VP cases might also be useful outside nursing and medical education. The results in this study showed that the students described an improved learning experience because the VP cases made them think more broadly and encouraged them to be more open minded to other options and to be more foresighted. Similar considerations have been seen in previous studies. One study showed that the review of options in the VP system and then receiving feedback, which allowed for an evaluation of the consequences, was particularly important for the students (Sandars, 2009). Another study found that VP cases trained the students in skills regarding critical thinking, communication, and decision-making (Sunnqvist et al., 2016). VP cases have the benefit of repeatedly providing the same experience and have the potential to provide students with opportunities to revisit the actions taken during the interaction with the "patient", thus allowing for comparison with best-practice protocols (Cendan \& Lok, 2012).

In this study, the students reported that they developed a structure for problem solving when they were working with the VP cases. A typical VP case session is built up as a stepwise unfolding of a scenario, first by assessing the patient, then deciding on various tests, diagnoses, and treatments, and then receiving feedback on the actions taken (Huwendiek, 2016). A previous study found that students experienced VPs in terms of characteristics associated with analytic reasoning, due to the VP systems structure and feedback, which helped them to organize their thoughts (Wilson, 2012). The results of this study showed that the students experienced a more comprehensive view of the situation or problem when utilizing VP cases. Previous research has found that students tend to have fragmented knowledge and tend to have a limited view of the patient from a holistic perspective (Frenk et al., 2010). Therefore, researchers have explored methods that might be used to improve the relevance, increase the reach, and accelerate the educational process for students (Crisp, Gawanas, \& Sharp, 2008), and VP systems are one such method. In addition, VP systems often provide tools for tracking the progress of the students (Cendan \& Lok, 2012). The students in this study described how the VP cases stimulated the learning process and how this inspired their reflection and encouraged them to search for more knowledge. The VP cases offered them a structure for systematic problem solving and provided an independent-learning approach. Most of the VP systems include an introduction to the case, patient interview questions, physical examinations, laboratory and imaging tests, and blood samples for proposing appropriate diagnoses and treatments and the justification for decisions about diagnosis and treatment and finally a feedback session (Bergin \& Fors, 2003). 
Earlier studies have shown that students have reported positive learning experiences from working with VP cases. They expressed that the VP cases reinforced self-directed learning in an active way and that they were stimulated to reflect on their actions. The students especially appreciated the fact that they received direct feedback to their answers and reflections (Salminen et al., 2014). Consequently, skills developed through the VP cases might be useful for learning experiences in various courses throughout higher education. Further research regarding such correlations might be of interest for the development of learning experiences in higher education.

The nursing students in this study described how the VP cases helped them to apply their learned theoretical knowledge in clinical practice and prepared them for their coming work in the nursing profession. A previous study showed that VP cases might bridge the gap between theoretical knowledge and clinical practice, and this supports an intermediate stage between basic science and clinical practice (Edelbring et al., 2011). Another study found that VP cases have the potential to provide students with opportunities to reconsider the actions they take in the interaction with the VP cases and then to compare their actions with best practice (Cendan \& Lok, 2012). VP cases have also been shown to be an educational strategy allowing students to replicate a set scenario as many times as needed, make mistakes, learn from their mistakes, receive appropriate feedback, trace a learning curve, and then improve the clinical skills that are essential in clinical practice, and they also have been shown to improve patient safety and to reduce stress when interacting with real patients (Ypinazar \& Margolis, 2006; Aper et al., 2014).

The results of the present study showed that students found the VP cases to be an important learning experience in addition to theoretical teaching and the literature. They expressed that their knowledge was strengthened and easier to retain when theory was combined with VP cases and then discussed in seminars. This is in line with previous research showing an improved learning process when using VP cases. The use of VP cases as a pedagogical strategy has shown improved knowledge retention and clinical reasoning in addition to increased student satisfaction (Padilha et al., 2018; Tschannen et al., 2012; Sperl-Hillen et al., 2014; Tiffany \& Hoglund, 2016). This study showed that students experienced the VP cases to be realistic and similar to clinical practice, and they described VP cases as an important opportunity to train abilities such as pattern recognition, clinical reasoning, and clinical decision-making. Further, they described improved self-confidence regarding their professional approach along with a more comprehensive view of the patient and how to act as a registered nurse. The students' descriptions might be interpreted as the VP cases having improved their clinical reasoning. Previous research has found that VP cases are well suited to support teaching, learning, and the assessment of students' clinical reasoning (Berman et al., 2016; Cook \& Triola, 2009; Huwendiek, Reichert et al., 2009), and other studies have also found the VP cases encourage and enhance clinical reasoning (Wilson, 2012; Gesundheit et al., 2009). Both analytic and 
non-analytic reasoning processes were found to be promoted in the students' descriptions of using VP cases (Eva, 2005). VP cases adapted for nursing education can support students in the development of their clinical reasoning by making the thinking strategies and tactics used in reflective clinical reasoning more explicit, and such a theory-anchored approach might be useful for further development.

Experiential learning theory (ELT) supports the learning experiences from VP cases regarding clinical reasoning, and the use of VP cases in nursing education might be understood through ELT (Kolb, 1984; Yardley et al., 2012) (Figure 1). In agreement with this theoretical model of action and reflection, VP cases expose students to simulated clinical experiences and provide mechanisms for information collection and clinical decision making in a secure environment (Edelbring et al., 2011). The VP cases in this study can be divided into the four learning stages according to Kolb (1984), where the students first undergo a Concrete Experience that creates the basis for further learning, then reflect upon the concrete experience (Reflective Observations) in order to understand the experience in a deeper way and thus formulate an understanding of abstract concepts (Abstract Conceptualization), and lastly Active Experimentation when the students are testing the implications in the given in-depth understanding. The results in this study regarding the students' descriptions of how working with VP cases encouraged them to think more broadly might be interpreted in relation to Concrete Experience. When the students started a VP case, they planned and tried out a new concrete experience (case). The students described an improved ability to draw conclusions and a developed structure for problem solving, which gave them a comprehensive view of the patients' situation. The students' statements related to how the VP cases stimulated their learning process might be connected to Reflective Observations. Work with VP cases challenged the students' knowledge through independent follow-ups, which inspired the students to reflect and motivated them to search for more knowledge. The learning stage of Abstract Conceptualization might be associated with the students' ability to translate theoretical knowledge into clinical reasoning. When the students combined theory and practice and then applied theory in practice,

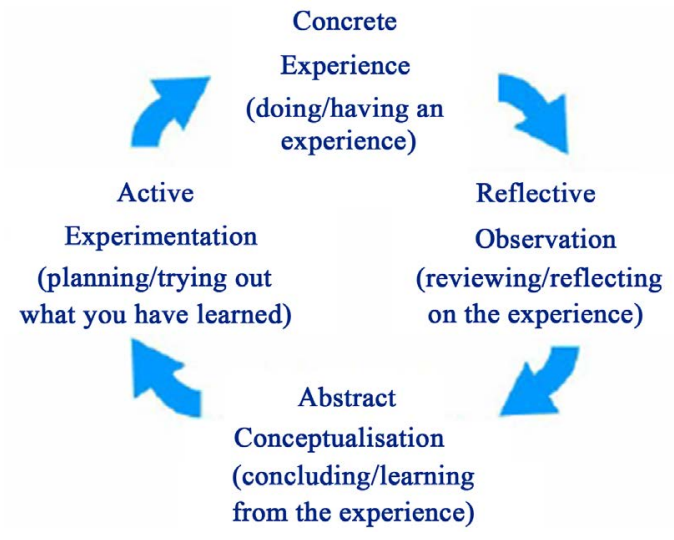

Figure 1. The experiential learning cycle (Kolb, 1984). 
they were supported in their clinical reasoning. Connected to the last stage of Active Experimentation, the students described how their knowledge was self-evaluated in the VP cases. The students received motivational feedback, which gave them an awareness of their abilities. Previous studies have found a similar pattern between the use of VP cases and ELT (Forsberg et al., 2016; George \& Zary, 2014; Konak et al., 2014). The students' use of VP cases in this study might be associated with a didactic method, which supports active student participation (ASP). Previous research has found that ASP provides students with a more active role in their own learning, which increases motivation, supports in-depth learning, and improves understanding of the subject (Barrineau et al., 2019; Bengtson et al., 2017). Consequently, VP cases have the potential to stimulate and motivate ASP in the learning of clinical reasoning (Forsberg, Ziegert, Hult, \& Fors, 2016). However, students might be even more active in their learning experiences if they are also involved in developing VP cases for next years' students.

A limitation of this study was the questionnaires with restricted open-ended questions, which elicited short answers from the students. A questionnaire with more open-ended questions would probably provide a wider range and greater variation of answers. However, the questionnaire had been tested and used in a previous study. Data collection with interviews would provide even more in-depth information from students about the use of VP cases. The study was carried out as part of a course in medical science, which limits the transfer of the results to other courses in nursing education, and studies evaluating VP cases in various courses will likely give a more comprehensive view of the learning experiences from VP cases in nursing education.

\section{Conclusion}

Studies have identified a lack of clinical reasoning skills among nurses, and existing pedagogical approaches do not always facilitate the development of nursing students' clinical reasoning. To teach and learn clinical reasoning is challenging because of its complexity, and it is difficult to make the clinical reasoning process visible and easy for the nursing students to grasp. Therefore, healthcare educators have tried to create learning activities to support students' ability to comprehend the clinical reasoning process. The intervention in this study implied that some teacher lectures were replaced by the fact that the students themselves had to solve VP cases individually and then discuss them in seminars. Further, the intervention was also aimed to promote active student participation, deep learning and peer tutoring. In this study, the students described how the VP cases encouraged them to think more broadly, stimulated the learning process, translated theory into clinical reasoning, and provided self-evaluation. The students experienced the VP cases to be realistic and similar to clinical practice, and they described VP cases as an important opportunity to train abilities such as pattern recognition, clinical reasoning, and clinical decision-making. They expressed that their knowledge was strengthened and 
easier to retain when theory was combined with VP cases and then discussed in seminars. The students also described improved self-confidence regarding their professional approach along with a more comprehensive view of the patient and how to act as a registered nurse. Learning experiences from VP cases seem to be applicable in higher education and in particular to enable nursing students to use theory in clinical practice. ELT supports the learning experiences from VP cases in clinical reasoning and promotes ASP.

\section{Acknowledgements}

The authors would like to express their gratitude to all nursing students in the courses who participated in the study. Thanks to professor Uno Fors of Stockholm University for letting us use the VP system, Web-SP, and thanks to the Center for Research on Welfare, Health and Sport (CVHI) at Halmstad University.

\section{Authors' Contributions}

EF and SK had the main responsibility for the conception, design, data collection, analysis, interpretation, and writing of the article. BB and EHT contributed to the data collection, analysis and interpretation of data, and revising the manuscript. All authors have approved the final submitted version of the manuscript.

\section{Conflicts of Interest}

The authors declare that they have no competing interests.

\section{References}

Aper, L., Reniers, J., Derese, A., \& Veldhuijzen, W. (2014). Managing the Complexity of Doing It All: An Exploratory Study on Students' Experiences When Trained Stepwise in Conducting Consultations. BMC Medical Education, 14, 206. https://doi.org/10.1186/1472-6920-14-206

Barrineau, S., Engström, A., \& Schnaas, U. (2019). An Active Student Participation Companion. Division for Quality Enhancement Unit for Academic Teaching and Learning. Uppsala, Sweden: Uppsala University.

Bengtson, C., Ahlqvist, M., Ekeroth, W., Nilsen-Moe, A., ProosVedin, N., Rodiuchkina, K., Ye, S., \& Lundberg, M. (2017).Working as Partners: Course Development by a Student-Teacher Team. International Journal for the Scholarship of Teaching and Learning, 11, Article 6. https://doi.org/10.20429/ijsotl.2017.110206

Bergin, R. A., \& Fors, U. G. (2003). Interactive Simulated Patient-An Advanced Tool for Student-Activated Learning in Medicine and Healthcare. Computers \& Education, 40, 361-376. https://doi.org/10.1016/S0360-1315(02)00167-7

Berman, N. B., Durning, S. J., Fischer, M. R., Huwendiek, S., \& Triola, M. M. (2016). The Role for Virtual Patients in the Future of Medical Education. Academic Medicine, 91, 1217-1222. https://doi.org/10.1097/ACM.0000000000001146

Bloomfield, J., Fordham-Clarke, C., Pegram, A., \& Cunningham, B. (2010). The Development and Evaluation of a Computer-Based Resource to Assist Pre-Registration 
Nursing Students with Their Preparation for Objective Structured Clinical Examinations (OSCEs). Nurse Education Today, 30, 113-117.

https://doi.org/10.1016/j.nedt.2009.06.004

Cendan, J., \& Lok, B. (2012). The Use of Virtual Patients in Medical School Curricula. Advances in Physiology Education, 36, 48-53.

Consorti, F., Mancuso, R., Nocioni, M., \& Piccolo, A. (2012). Efficacy of Virtual Patients in Medical Education: A Meta-Analysis of Randomized Studies. Computers \& Education, 59, 1001-1008. https://doi.org/10.1016/j.compedu.2012.04.017

Cook, D. A., \& Triola, M. M. (2009). Virtual Patients: A Critical Literature Review and Proposed Next Steps. Medical Education, 43, 303-311. https://doi.org/10.1111/j.1365-2923.2008.03286.x

Cook, D. A., Erwin, P., \& Triola, M. M. (2010). Computerized Virtual Patients in Health Professions Education: A Systematic Review and Meta-Analysis. Academic Medicine, 85, 1589-1602. https://doi.org/10.1097/ACM.0b013e3181edfe13

Crisp, N., Gawanas, B., \& Sharp, I. (2008). Training the Health Workforce: Scaling Up, Saving Lives. The Lancet, 371, 689-691. https://doi.org/10.1016/S0140-6736(08)60309-8

Delany, C., \& Golding, C. (2014). Teaching Clinical Reasoning by Making Thinking Visible: An Action Research Project with Allied Health Clinical Educators. BMC Medical Education, 14, 20. https://doi.org/10.1186/1472-6920-14-20

Edelbring, S., Dastmalchi, M., Hult, H., Lundberg, I. E., \& Dahlgren, L. O. (2011). Experiencing Virtual Patients in Clinical Learning: A Phenomenological Study. Advances in Health Sciences Education, 16, 331-345. https://doi.org/10.1007/s10459-010-9265-0

Ellaway, R., Poulton, T., Fors, U., McGee, J. B., \& Albright, S. (2008). Building a Virtual Patient Commons. Medical Teacher, 30, 170-174.

https://doi.org/10.1080/01421590701874074

Eva, K. W. (2005). What Every Teacher Needs to Know about Clinical Reasoning. Medical Education, 39, 98-106. https://doi.org/10.1111/j.1365-2929.2004.01972.x

Forsberg, E., Georg, C., Ziegert, K., \& Fors, U. (2011). Virtual Patients for Assessment of Clinical Reasoning in Nursing-A Pilot Study. Nurse Education Today, 31, 757-762. https://doi.org/10.1016/j.nedt.2010.11.015

Forsberg, E., Ziegert, K., Hult, H., \& Fors, U. (2014). Clinical Reasoning in Nursing, a Think-Aloud Study Using Virtual Patients-A Base for an Innovative Assessment. Nurse Education Today, 34, 538-542. https://doi.org/10.1016/j.nedt.2013.07.010

Forsberg, E., Ziegert, K., Hult, H., \& Fors, U. (2016). Assessing Progression of Clinical Reasoning through Virtual Patients: An Exploratory Study. Nurse Education in Practice, 16, 97-103. https://doi.org/10.1016/j.nepr.2015.09.006

Frenk, J., Chen, L., Bhutta, Z. A., Cohen, J., Crisp, N., Evans, T., Fineberg, H., Garcia, P., Ke, Y., Kelley, P., Kistnasamy, B., Meleis, A., Naylor, D., Pablos-Mendez, A., Reddy, S., Scrimshaw, S., Sepulveda, J., Serwadda, D., \& Zurayk, H. (2010). Health Professionals for a New Century: Transforming Education to Strengthen Health Systems in an Interdependent World. The Lancet, 376, 1923-1958. https://doi.org/10.1016/S0140-6736(10)61854-5

Georg, C., \& Zary, N. (2014). Web-Based Virtual Patients in Nursing Education: Development and Validation of Theory-Anchored Design and Activity Models. Journal of Medical Internet Research, 16, e105. https://doi.org/10.2196/jmir.2556

Gesundheit, N., Brutlag, P., Youngblood, P., Gunning, W. T., Zary, N., \& Fors, U. (2009). The Use of Virtual Patients to Assess the Clinical Skills and Reasoning of Medical Students: Initial Insights on Student Acceptance. Medical Teacher, 31, 739-742.

https://doi.org/10.1080/01421590903126489 
Graneheim, U. H., \& Lundman, B. (2004). Qualitative Content Analysis in Nursing Research: Concepts, Procedures and Measures to Achieve Trustworthiness. Nurse Education Today, 24, 105-112. https://doi.org/10.1016/j.nedt.2003.10.001

Hsieh, H. F., \& Shannon, S. E. (2005). Three Approaches to Qualitative Content Analysis. Qualitative Health Research, 15, 1277-1288. https://doi.org/10.1177/1049732305276687

Hunter, S., \& Arthur, C. (2016). Clinical Reasoning of Nursing Students on Clinical Placement: Clinical Educators' Perceptions. Nurse Education in Practice, 18, 73-79. https://doi.org/10.1016/j.nepr.2016.03.002

Huwendiek, S. (2016). Virtual Patients for Learning of Clinical Reasoning. Doctoral Thesis, Maastricht, Netherlands: Maastricht University.

Jessee, M. A., \& Tanner, C. A. (2016). Pursuing Improvement in Clinical Reasoning: Development of the Clinical Coaching Interactions Inventory. Journal of Nursing Education, 55, 495-504. https://doi.org/10.3928/01484834-20160816-03

Johannesson, E., Silén, C., Kvist, J., \& Hult, H. (2013). Students’ Experiences of Learning Manual Clinical Skills through Simulation. Advances in Health Sciences Education, 18, 99-114. https://doi.org/10.1007/s10459-012-9358-Z

Kolb, D. A. (1984). Experiential Learning: Experience as the Source of Learning and Development (Vol. 1). Englewood Cliffs, NJ: Prentice-Hall.

Konak, A., Clark, T. K., \& Nasereddin, M. (2014). Using Kolb’s Experiential Learning Cycle to Improve Student Learning in Virtual Computer Laboratories. Computers \& Education, 72, 11-22. https://doi.org/10.1016/j.compedu.2013.10.013

Kononowicz, A., Zary, N., Edelbring, S., Corral, J., \& Hege, I. (2015). Virtual Patients-What Are We Talking about? A Framework to Classify the Meanings of the Term in Healthcare Education. BMC Medical Education, 15, 11. https://doi.org/10.1186/s12909-015-0296-3

Levett-Jones, T., Hoffman, K., Dempsey, J., Jeong, S. Y., Noble, D., Norton, C. A., Roche, J., \& Hickey, N. (2010). The 'Five Rights' of Clinical Reasoning: An Educational Model to Enhance Nursing Students' Ability to Identify and Manage Clinically 'at Risk' Patients. Nurse Education Today, 30, 515-520. https://doi.org/10.1016/j.nedt.2009.10.020

Mishra, A., Rani, S., \& Bhardwaj, U. D. (2017). Effectiveness of E-learning Module on First Aid: A Study on Student Nurses. International Journal of Nursing Education, 9, 6-10. https://doi.org/10.5958/0974-9357.2017.00060.5

Padilha, J. M., Machado, P., Ribeiro, A., \& Ramos, J. (2018). Clinical Virtual Simulation in Nursing Education. Clinical Simulation in Nursing, 15, 13-18. https://doi.org/10.1016/j.ecns.2017.09.005

Salminen, H., Zary, N., Björklund, K., Toth-Pal, E., \& Leanderson, C. (2014). Virtual Patients in Primary Care: Developing a Reusable Model That Fosters Reflective Practice and Clinical Reasoning. Journal of Medical Internet Research, 16, e3. https://doi.org/10.2196/jmir.2616

Sandars, J. (2009). The Use of Reflection in Medical Education: AMEE Guide No. 44. Medical Teacher, 31, 685-695. https://doi.org/10.1080/01421590903050374

Statens Offentliga Utredningar (SOU) (2016). För digitalisering i tiden. Slutbetänkande av Digitaliseringskommissionen (No. 89). Stockholm. https://www.regeringen.se/4af25c/contentassets/f7d07b214e2c459eb5757cea206e6701/s ou-2016_89_webb.pdf https://www.regeringen.se/4af25c/contentassets/.../sou-2016_89_webb.pdf

Sperl-Hillen, J., O’Connor, P. J., Ekstrom, H. L., Rush, W. A., Asche, S. E., Fernandes, O. D., Apana, D., Amundson, G. H., Johnson, P. E., \& Curran, D. M. (2014). Educating 
Resident Physicians Using Virtual Case-Based Simulation Improves Diabetes Management: A Randomized Controlled Trial. Academic Medicine, 89, 1664-1673. https://doi.org/10.1097/ACM.0000000000000406

Sunnqvist, C., Karlsson, K., Lindell, L., \& Fors, U. (2016). Nurse Education in Practice Virtual Patient Simulation in Psychiatric Care: A Pilot Study of Digital Support for Collaborative Learning. Nurse Education in Practice, 17, 30-35.

https://doi.org/10.1016/j.nepr.2016.02.004

Tiffany, J. M., \& Hoglund, B. (2016). Using Virtual Simulation to Teach Inclusivity: A Case Study. Clinical Simulation in Nursing, 12, 115-122. https://doi.org/10.1016/j.ecns.2015.11.003

Tschannen, D., Aebersold, M., McLaughlin, E., Bowen, J., \& Fairchild, J. (2012). Use of Virtual Simulations for Improving Knowledge Transfer among Baccalaureate Nursing Students. Journal of Nursing Education and Practice, 2, 15-24. https://doi.org/10.5430/jnep.v2n3p15

Wilson, J. I. (2012). A Qualitative Study of Postgraduate Students' Perceptions of Virtual Patients in Emergency Medicine Tutorials. International Journal of Medical Education, 3, 115-123. https://doi.org/10.5116/ijme.4fea.1918

Yardley, S., Teunissen, P. W., \& Dornan, T. (2012). Experiential Learning: AMEE Guide No. 63. Medical Teacher, 34, e102-e115. https://doi.org/10.3109/0142159X.2012.650741

Ypinazar, V. A., \& Margolis, S. A. (2006). Clinical Simulators: Applications and Implications for Rural Medical Education. Rural and Remote Health, 6, 527.

Zary, N., Johnson, G., Boberg, J., \& Fors, U. G. (2006). Development, Implementation and Pilot Evaluation of a Web-Based Virtual Patient Case Simulation Environment-Web-SP. BMC Medical Education, 6, 10.

https://doi.org/10.1186/1472-6920-6-10 